\title{
Analysis for the Free E-Commerce Pattern
}

\author{
WANG Anbao* \\ School of Computer and Information, Shanghai Second \\ Polytechnic University, Shanghai 201209, China \\ wabhappy@163.com
}

\author{
XING Haoran \\ School of Computer and Information, Shanghai Second \\ Polytechnic University, Shanghai 201209, China \\ xinghaoran0099@hotmail.com
}

\begin{abstract}
Nowadays, when free trial has become a powerful marketing measure, it is possible that we may experience a "free lunch". This paper analyzes the free economic pattern, free economic pattern has made an attempt in early 20th century, and "free" has gradually impelled a consumption revolution. It is the direction of marketing in both recent years and the future. Faced with such situations, how these enterprises in internet to made relative solution to resist the impact of "free".
\end{abstract}

Keywords-the Free E-Commerce, Website Pattern; Causes for free; Survive in free; E-Commerce.

\section{Introduction}

If I want to buy a game machine, the first thing I would like to do is open the Aoyou browser and enter the taobao. While doing this, I will chat with my friends on QQ, and search the parameters of the game machine through Baidu Search Engine. Then I can use Alipay which is a safe payment software provided by taobao. In such processes, 360safe will protect my online trading. The browser, anti-virus software, chatting software and other services I use are all free, what I need to pay is the price of the game machine itself.

When free trial has become a powerful marketing measure, it is possible that we may experience a "free lunch". Since free economic pattern has made an attempt in early 20th century, "free" has gradually impelled a consumption revolution. It is the direction of marketing in both recent years and future. Faced with such situations, all enterprises in internet apparently try all means to create more perfect free product which are for consumers.

\section{The causes for free}

The shaver of Gin Gilly was appeared in the year of 1903, and the sales volume was only 51 shavers and 168 blades. But the founder of Gin Gilly sold these shavers to army and banks at a low price, and later he even gave shavers as gifts to those people who have bought the blades. Because it could increase the need of blades, if people had a shaver for free. Up to now, Gilly Corporation has sold out billions of blades successfully. It is a great marketing measure that a complimentary production can increase the need of other production. Gin Gilly just adopts this measure to access to market.

What is free economic pattern indeed? According to Chris Anderson, "free" is a kind of economics which is not founded on the old principle of physics, but on computer byte. That is to say, in such an internet digital age, the cost of distribution and manufacture approaches to zero. The business can pay more attention on other profit than only on the production itself. Just as in the microgroove market, you can only tap the button of download, and then you can hear kinds of music [1]. It seems to be a disaster of musicians and these companies for it already non-profit. One can take another look at this, musicians can offer free music to people to create a wider market, and make profit in polyphonic ringtone, concert, and advertisement and so on. This is a train of thought in free pattern.

"Free" is very important in the minds of consumers. People's attitude to "free" is relative. If a chargeable product is suddenly free of charge, consumers will be suspicious about the reason of free. Is there something wrong with this product? But this suspicion will never occur in the free product. For instance, if the boss gives you a free pot-stewed chicken when you pass by a delicatessen and you would think the chicken must be deteriorate. But this would never occur in the free seasoning of a noodle restaurant.

The explanation of such case in free psychology is that, no matter how much the charge will be, it would be enable us to think about the cost. When faced with such charge, we will think about whether it worthy the money or not. However, we would have no such consideration when faced with free product. Nic Sable, in University of Washington, uses "mental transaction costs" to define such situation. Briefly, it is the cost of consideration. Indolence is human nature, and people always avoid consideration, so we often choose thing need not to ponder on. There is a good instrument when we must make a decision. That is "choice probability formula" which is advocated by Wilbur Schramm, the founder of Communication.

Information Choice probability= Reward guarantee/arduous degree

People always ponder the difficult degree of access the information and the validity of information. Although it only an information choice formula, it also can explain the reason of the birth of "free".

Wilbur Schramm analyzed the free strategy that the Google adopted. It can well explain the causes for free. He called it as "The Maximization Strategy", namely, "all the products you develop will accept it, and produce them as much as possible according to the distribution. That is to say, since the marginal cost of distribution is zero, then you can make your products all over the world." In simple terms, free can makes the enterprise maximize the market share and make profits.

Actually free is a double-edged sword. Any of the Internet enterprises are afraid to try to shift from free to fee easily. But on the other hand, the increasing pressure of competition 
makes Internet enterprises have to create new profit model. Free mode also arises under such a historic moment.

\section{The Free Economic Pattern}

Free is not equal to non-profitable. The Google -the first internet enterprise in the world, has more than one hundred free products, which are include search engine, spreadsheet, and map. But free does not impede Google to be a searching tycoon which counts for 20 billion.

Then, how to make profit behind free? Chris Anderson, who was known as the spiritual leader of the information age, once assorts the free economic pattern into such six kinds.

Freemium. It combines free with fee together, namely freefee pattern. In other words, it is a website or software with more specialties and merits than free model. A typical website often follows the $1 \%$ principle- $1 \%$ of consumers have supported other $99 \%$ of consumers. For example, an ordinary consumer of Xunlei can download certain things for free, while consumers also can pay some money to download at a high speed. Such consumers are one of the income streams of the software.

Advertisement. It is the most common pattern which is referring to the content, services and software. The ads on the internet have become a hottest form. The businesses offer free products and services to attract consumers who are just the ads wants to an impact on.

Cross-subsidies. Free lunch has rooted in the cocktail lounge of San Francisco in 19th century. One can have a free meal when he buys a jar of beer. This is the same as "prestore the telephone fare". As a matter of fact, the cost of all of the products and services, or even a single production is often rested on the thoughts of consumers, not on the really costs [2].

Zero marginal cost. No such things that can describe this kind of pattern. At the stimulation of the transmission lines of digital, replication and p2p, the actual cost of the musical production is next to zero, so that the barriers made by the laws, morals and lots of pirates gradually go to bankruptcy.

Labor exchange. You can get samples from a certain famous brand as long as you fill in questionnaires. Or you can get more online money if you play for a longer time. These actions actually make some values, but the gains seem as free.

Gift economy. It includes many resources such as open source software. For instance, Baidu Pedia will compile the guidebook for consumers who do not enroll in [3].

In the age of electronic commerce, free is an important strategy of surpassing and defeating competitors. Before the appearance of Taobao, Eachnet, which was established by two graduates -Tan Haiyin and Hao Yibo, graduated from Harvard Business School, occupied a dominant position in the market of B2C and C2C. Eachnet began to get money from the products in July 2001. After that, the service payment from the sellers of the products would follow after the deal. The Eachnet went into the time of anti-free occupation at the stage of electronic commerce then, which was the landmark of the development of the Chinese electronic commerce. In 2003, after ebay had purchased the stock of Eachnet (American) company, Eachnet began the overall cooperation with ebay to continue the project of charging. At the same time, Taobao began to sell on line and announced that the selling was free for whole website, so that the time of Taobao was coming. And it began the journey of usurpation, which was the turning point of Eachnet[4].

Taobao gradually set up charge items such as Taobao Mall which strictly implement the strategy of free enrichment. They make profit by optimize services, while most of services are for free. It can be said like this, Taobao has exceeded ebay at the very beginning of the battle. Although the two are both profitable, but ebay was forced to free from making money. On the other hand, Taobao took possession of the market at first and then turned to make profit. This can be well demonstrated by the change of marker share.

Besides the support of Alibaba, which mastered B2B, the painstaking transaction, and marketing activities, the key point is the strategy of free. Taobao always pay much attention on its image in consumers and media, so it has announced many times that it will adhere to the strategy of free. Up to now, Taobao has been free all along. Some people criticize that Taobao's covert act of charging money, such as the Taobao mall and competitive bidding ranking, which is named as "invite the God of Wealth". They say these actions violate the promise of being free. Despite such comments, the free pattern has defeated charging money. But eventually, free will turn back to charging money. It is worth to mention that the service of competitive bidding ranking has dropped out of Taobao.

\section{How the enterprises survive in free}

Some enterprises would still want to charge money for those products that have already free, but in such a crucially commercial competition, the idea will limited by the competition. Unless the products absolutely monopolize the market, otherwise, enterprises will be continually tempted to lower the price, or even being free to raise the market share and sales volume. The new entrants will lower their price to the stage of free. In internet, particular in electronic commerce of China, the market is very complex. Because our market of C2C is not pure, it is mixed with B2C. Therefore, in such a complex market, one must has insight of the market demand, and changes followed by the change of the demand. For the pattern of free economy, enterprises should initiatively offer their products free to some extent and get familiar with the relationship of free and charging, rather than treat it passive or ignore its existence. In this way, a enterprise can survival in the free economic pattern.

Almost all the services of payment are established on the base of the free service, and there are three aspects of connection between the free one and pay one. Firstly, both are in the situation of the payment produced by the sequence of rank which is born by the search result, such as the biding price ranking of Baidu. Secondly, the connection comes from the prior service and added charge environment which bases on free service, such as the distinguish between the VIP member and non-VIP member of Tencent, and the receiving situation between charge item and free item of on-line shopping. The 
electronic commercial websites belong to this category, such as Taobao mall and the ordinary sellers. The third connection between them comes from the third-party profits produced by the increase of number of consumers and the raise of demands [5]. For instance, Renren has controlled the most users among the social websites for students, while the money has to be paid when the advertisements and the third software want to login.

If the enterprises can deeply understand the third connection between the free one and the pay one, they can occupy the survival opportunity in this time of internet digitalization. At last, one point must be emphasized: "free" is not mighty. In other words, "free" will not make the enterprises richer, so they have to creatively think about how to get the market share and the reputation from free, and then turn them into profits. So, this is the way of survive for the enterprises.

\section{Conclusions}

Through these analysis, we know the free trial has become a powerful marketing measure, and the free economic pattern has made an attempt in early 21th century. It is the direction of marketing in both recent years and the future. Faced with such situations, all enterprises in internet apparently try all means to create more perfect free product which are for consumers.

\section{References}

[1] Chris Andersen. The Future of Radical Price [J] (in Chinese). China Business Beview , 2008.5:54-56

[2] [2] Sheng Xiaobai. The Theoretic Mode of "Free Economy" [J] (in Chinese). Audit and Economy Research, 2006,21(06):67-69

[3] [3] Zhang Ning. Free Economics: Who Pays for You? [J] (in Chinese), Asian Business Leaders, 2008,5:22-23

[4] [4] Zhou Geng. Case Analysis of Taobao and Ebay--with discussion of the development of C2C (in Chinese) [J]. Modern Management Science, 2008, 3:62-63.

[5] [5] Chris Andersen. The Long Tail: Why the Future of Business Is Selling Less of More [J] (in Chinese), CHINA BUSINESS REVIEW. 2007, 6:114-121. 